\title{
Fungicidal activities and mechanisms of action of Pseudomonas syringae pv. syringae lipodepsipeptide syringopeptins 22A and 25A
}

\author{
Mekki F. Bensaci ${ }^{1 \dagger}$, Philip A. Gurnev ${ }^{2}$, Sergey M. Bezrukov ${ }^{2}$ and Jon Y. Takemoto ${ }^{1 *}$ \\ Department of Biology, Utah State University, Logan, UT, USA \\ 2 Program in Physical Biology, Eunice Kennedy Shriver National Institute of Child Health and Human Development, National Institutes of Health, Bethesda, MD, USA
}

\section{Edited by:}

Ana Traven, Monash University, Australia

\section{Reviewed by:}

Anand K. Ramasubramanian

University of Texas at San Antonio, USA

Dennis Gross, Texas A\&M University, USA

\section{*Correspondence:}

Jon Y. Takemoto, Department of Biology, Utah State University, 5305 Old Main Hill, Logan, UT 84322-5305, USA.

e-mail: jon@biology.usu.edu

\section{${ }^{\dagger}$ Current Address:}

Mekki F. Bensaci, Division of Geographic Medicine and Infectious Diseases, Tufts Medical Center, Boston, MA, USA.
The plant-associated bacterium Pseudomonas syringae pv. syringae simultaneously produces two classes of metabolites: the small cyclic lipodepsinonapeptides such as the syringomycins and the larger cyclic lipodepsipeptide syringopeptins SP22 or SP25. The syringomycins inhibit a broad spectrum of fungi (but particularly yeasts) by lipid-dependent membrane interaction. The syringopeptins are phytotoxic and inhibitory to Gram-positive bacteria. In this study, the fungicidal activities of two major syringopeptins, SP22A and SP25A, and their mechanisms of action were investigated and compared to those of syringomycin E. SP22A and SP25A were observed to inhibit the fungal yeasts Saccharomyces cerevisiae and Candida albicans although less effectively than syringomycin E. S. cerevisiae mutants defective in ergosterol and sphingolipid biosyntheses were less susceptible to SP22A and SP25A but the relative inhibitory capabilities of SRE vs. SP22A and SP25A were maintained. Similar differences were observed for capabilities to cause cellular $\mathrm{K}^{+}$and $\mathrm{Ca}^{2+}$ fluxes in S. cerevisiae. Interestingly, in phospholipid bilayers the syringopeptins are found to induce larger macroscopic ionic conductances than syringomycin $E$ but form single channels with similar properties. These findings suggest that the syringopeptins target the yeast plasma membrane, and, like syringomycin $E$, employ a lipid-dependent channel-forming mechanism of action. The differing degrees of growth inhibition by these lipodepsipeptides may be explained by differences in their hydrophobicities. The more hydrophobic SP22A and SP25A might interact more strongly with the yeast cell wall that would create a selective barrier for their incorporation into the plasma membrane.

Keywords: syringopeptin, fungicide, syringomycin, yeast, Pseudomonas syringae, ion channel

\section{INTRODUCTION}

In addition to well-characterized small cyclic lipodepsinonapeptides, Pseudomonas syringae pv. syringae produces larger cyclic lipodepsipeptides known as the syringopeptins. These compounds are composed of 22 or 25 amino acids (SP22 and SP25, respectively) with an octadepsipeptide ring structure and a 3-hydroxy fatty acyl chain. Isoforms of SP22 and SP25 possessing fatty acyl chains composed of 10 and 12 carbons are designated A and B homologs, respectively. They or close structural variants are produced by other P. syringae pathovars (Vassilev et al., 1996; Grgurina et al., 2005). The syringopeptins are phytotoxic, and also have antimicrobial activities against Gram-positive bacteria (Lavermicocca et al., 1997; Grgurina et al., 2005; Bensaci and Takemoto, 2007). However, little is known about the antifungal properties of the syringopeptins although inhibitory activities against yeasts including the pathogen Candida albicans are briefly mentioned in reports (Iacobellis et al., 1992; Lavermicocca et al., 1997; Grgurina et al., 2005).

The small cyclic lipodepsinonapeptide syringomycin E (SRE) acts on yeast plasma membranes to cause increases in cellular
$\mathrm{K}^{+}$efflux and transient $\mathrm{Ca}^{2+}$ fluxes (Zhang and Takemoto, 1989; Takemoto et al., 1991). The effects are consistent with SRE's ability to form ion-conducting voltage sensitive channels in planar lipid bilayers (Feigin et al., 1996; Kaulin et al., 1998; Malev et al., 2002). Studies with yeast lipid mutants revealed that sphingolipids and sterols (lipids that predominate in the plasma membrane) modulate SRE's fungicidal activity (Cliften et al., 1996; Grilley et al., 1998; Stock et al., 2000). Lipid-modulated clustering of single channels each composed of six SRE molecules has been proposed as the structural basis for SRE's mechanism of action on membranes (Kaulin et al., 1998, 2005; Malev et al., 2002).

Less is known about the mechanisms of action of the syringopeptins. A few studies have shown that the syringopeptins are capable of forming ion-conducting membrane channels (Hutchison and Gross, 1997; Dalla Serra et al., 1999; Agner et al., 2000). In lipid bilayers and erythrocytes, SP22A channels do not thermally inactivate as do SRE channels - a phenomenon related to SP22A's greater effectiveness in ordering membrane lipids (Szabo et al., 2004). In plant systems, the syringopeptins have been shown to cause electrolyte leakage in leaf tissues (Iacobellis 
et al., 1992; Lavermicocca et al., 1997), to increase the permeability of tonoplasts (Carpaneto et al., 2002), close stomata (Di Giorgio et al., 1996a), and modify $\mathrm{H}^{+}$fluxes across mitochondria and plasma membranes (Di Giorgio et al., 1994, 1996b). Finally, syringopeptins interact with bacterial cell surface teichoic acids (Bensaci and Takemoto, 2007), but whether and how they act on bacterial membranes is still unknown. Despite recognition that the syringopeptins are antifungal, there are no published studies devoted to the fungicidal mechanisms of action of syringopeptins.

In this study, we addressed the relationship between fungicidal activity and the mechanism of action of the syringopeptins. Despite structural differences between the syringopeptins and SRE, we show that the physiological responses and the membrane lipid requirements for growth inhibition are similar but the degrees of effectiveness differ in the order: SRE $>$ SP22A $>$ SP25A. To examine the basis for these differences, the channel-forming properties of the syringopeptins in lipid bilayers in comparison with those of SRE were investigated. It was found that in planar lipid bilayers SP22A and SP25A induce larger macroscopic conductances than SRE but form single channels of very similar properties.

\section{MATERIALS AND METHODS YEAST STRAINS}

Saccharomyces cerevisiae SRE-sensitive strains KZ1-1C, 8A-1B, W303C, and BY4741 and SRE-resistant and lipid biosynthesis mutant strains $\Delta$ erg3, $\Delta s y r 2, \Delta i p t 1, \Delta e l o 2, \Delta e l o 3$, and $\Delta$ fah1 were described previously (Taguchi et al., 1994; Hama et al., 2000; Stock et al., 2000). SRE-resistant strains $\Delta \operatorname{erg} 3$ (formerly $\Delta$ syrl, Taguchi et al., 1994) and $\Delta f a h 1$ are single-gene disruptants and isogenic to parental strains $8 \mathrm{~A}-1 \mathrm{~B}$ and BY4741, respectively. All other SRE-resistant mutants are single-gene disruptants and isogenic to parental strain W303C. C. albicans ATCC10231 was obtained from the American Type Culture Collection (Manassas, VA, USA). All yeast strains were grown at $28^{\circ} \mathrm{C}$ and maintained $\left(\right.$ at $5^{\circ} \mathrm{C}$ ) with yeast extract-peptone dextrose (YPD) broth or agar medium (Hama et al., 2000).

\section{PURIFICATION OF SRE, SP22A, AND SP25A}

SRE $\left(M_{\mathrm{r}}\right.$ 1224) was purified from $P$. syringae pv. syringae strains B301D or M1 by previously described methods of Bidwai et al. (1987), Adetuyi et al. (1995). SP22A ( $\mathrm{M}_{\mathrm{r}}$ 2142) and SP25A ( $\mathrm{M}_{\mathrm{r}}$ 2397) were purified from extracts of strains P. syringae pv. syringae B301D and M1 respectively, using methods described earlier (Bensaci and Takemoto, 2007).

\section{GROWTH INHIBITION}

For measuring growth inhibition in liquid batch cultures, S. cerevisiae strain KZ1-1C was first grown in YPD broth medium at $28^{\circ} \mathrm{C}$ in $125 \mathrm{~mL}$ capacity Erlenmeyer flasks with rotary shaking for $48 \mathrm{~h}$ to a density of $\sim 8 \times 10^{8}$ cells $\mathrm{mL}^{-1}$. The cells were centrifuged and the sedimented cells suspended in YPD broth medium to give $2.4 \times 10^{7}$ cells $\mathrm{mL}^{-1}$. SRE, SP22A, or SP25A were added at designated concentrations (between 0.8 and $9.3 \mu \mathrm{M}$ ). The suspensions were incubated with rotary shaking at $28^{\circ} \mathrm{C}$ and samples removed hourly for direct cell counts using a light microscope and hemocytometer. Minimal inhibitory concentrations (MICs) were determined by the microbroth dilution assay according to methods of the National Committee of Clinical Laboratory Standards (NCCLS, 2002). Yeast strains were grown to a final concentration of $10^{8}$ colony-forming units (CFU) $\mathrm{mL}^{-1}$ and suspended at a final concentration of $5 \times 10^{5} \mathrm{CFU} \mathrm{mL}^{-1}$. Cell suspensions $(25 \mu \mathrm{L})$ were added to $25 \mu \mathrm{L}$ aliquots of twofold serial dilutions of SRE, SP22A, and SP25B. YPD broth media were dispensed $(100 \mu \mathrm{L}$ total volume) in wells of 96 -well polystyrene microtiter plates. The plates were incubated for $24 \mathrm{~h}$ at $28^{\circ} \mathrm{C}$. The MICs were determined by visual inspection of the plate. For determination of cell viability, a suspension of $4 \times 10^{5} \mathrm{CFU} \mathrm{mL}^{-1}$ was treated with different concentrations of SRE, SP22A, and SP25A and the cell suspension was twofold serially diluted. Aliquots $(100 \mu \mathrm{L})$ were spread-plated onto YPD agar, the agar plates incubated for $24-48 \mathrm{~h}$ at $28^{\circ} \mathrm{C}$, and the numbers of colony-forming units per milliliter of undiluted cell suspension determined. All growth inhibitory experiments were performed in triplicate and the results reported as mean values.

\section{$\mathbf{K}^{+}$EFFLUX}

Whole cell $\mathrm{K}^{+}$efflux rates were determined as changes in extracellular $\mathrm{K}^{+}$concentrations. Yeast strain $\mathrm{KZ1-1C}$ was grown in YPD broth medium with rotary shaking at $28^{\circ} \mathrm{C}$ to a density of $10^{8}$ cells $\mathrm{mL}^{-1}$. Cells were suspended in $2 \mathrm{mM}$ Tris/MES buffer, $\mathrm{pH}$ 6.5, and 0.1 M-glucose with or without SRE, SP22A, or SP25A (at concentrations of 1,10 , or $100 \mu \mathrm{M}$ ) to $A_{600} \mathrm{~nm}$ of 1 in $125 \mathrm{~mL}$ capacity Erlenmeyer flasks with rotary shaking $(200 \mathrm{rpm})$ at $28^{\circ} \mathrm{C}$ (Takemoto et al., 1991). At $5 \mathrm{~min}$ after suspension, $1 \mathrm{~mL}$ samples were withdrawn, centrifuged in an Eppendorf microcentrifuge for $30 \mathrm{~s}$, and the supernatant fractions were recovered. $\mathrm{K}^{+}$concentrations were determined by atomic absorption spectroscopy (AA/AE spectrophotometer 457, Instrumentation Laboratories).

\section{CA $^{2+}$ UPTAKE}

The net cellular uptake of ${ }^{45} \mathrm{Ca}^{2+}$ was measured using strain KZ1-1C as described previously (Takemoto et al., 1991). Cells were grown in YPD broth medium to a density of $1 \times 10^{7}$ cells $\mathrm{mL}^{-1}$, harvested by centrifugation, and then suspended in YPD broth medium to a density of $4 \times 10^{7}$ cells $\mathrm{mL}^{-1}$ ). Ten milliliter aliquots were dispensed in $125 \mathrm{~mL}$ capacity Erlenmeyer flasks with radioactive ${ }^{45} \mathrm{CaCl}_{2}$ (Amersham Radiochemicals) and incubated with rotary shaking $(200 \mathrm{rpm})$ at $28^{\circ} \mathrm{C}$. The specific radioactivity of ${ }^{45} \mathrm{Ca}^{2+}$ was adjusted to $4 \mathrm{mCi}(148 \mathrm{MBq})$ per millimole of $\mathrm{CaCl}_{2}$ (Takemoto et al., 1991). SRE, SP22A, or SP25A were added 5 min following addition of ${ }^{45} \mathrm{CaCl}_{2}$. At designated times, cell samples $(200 \mu \mathrm{L})$ were collected on glass fiber filters $(0.45 \mu \mathrm{M}$ pore size $)$, the filters were quickly washed twice with ice-cold water, and the radioactivity on the filters determined using a liquid scintillation counter.

\section{CHANNEL FORMATION IN PLANAR LIPID BILAYERS}

Lipid bilayer electrophysiological experiments were performed using 1,2-dioleoyl-sn-glycero-3-phosphorylcholine (DOPC; Avanti Polar Lipids) as previously described (Blasko et al., 1998; Malev et al., 2002). Solutions of $0.1 \mathrm{M} \mathrm{NaCl}$ were buffered with $5 \mathrm{mM}$ MOPS (Sigma) to $\mathrm{pH}$ 6. Bilayer lipid membranes were prepared by a monolayer-opposition technique (Montal and Mueller, 1972) on 
a 50 - to $100-\mu \mathrm{m}$ diameter aperture in the $15-\mu \mathrm{m}$ thick Teflon film separating two (cis and trans) compartments of a Teflon chamber. SP22A, SP25A, and SRE were added to the aqueous phase of the cisside compartment. A pair of $\mathrm{Ag} / \mathrm{AgCl}$ electrodes with agarose/2 $\mathrm{M}$ $\mathrm{KCl}$ bridges was used to apply transmembrane voltages and to measure single-channel currents. All experiments were performed at room temperature $\left(22 \pm 2^{\circ} \mathrm{C}\right)$. Current measurements were carried out using an Axopatch $200 \mathrm{~B}$ amplifier (Axon Instruments) in a voltage clamp mode. The data were filtered with a low-pass 8pole Model 9002 Bessel filter (Frequency Devices) at $1 \mathrm{kHz}$ and directly recorded into computer memory with a sampling frequency of $5 \mathrm{kHz}$. Data were analyzed using pClamp 9.2 (Axon Instruments) and Origin 7.0 (Origin Lab). Current transition histograms were generated for each tested voltage. Histogram peaks were fitted with the normal distribution function. Single-channel conductance was calculated as the mean single-channel current divided by the applied transmembrane voltage.

\section{RESULTS}

\section{GROWTH INHIBITORY ACTIVITIES AGAINST YEASTS}

SRE and syringopeptins SP22A and SP25A inhibited the growth of different strains of S. cerevisiae and C. albicans ATCC 10231 (Table 1). In all cases, SP22A was $\sim 2$-fold more active than SP25A and both were less inhibitory than SRE. The same relative inhibitory capabilities (i.e., SRE $>$ SP22A $>$ SP25A) were observed when measuring effects on cell numbers in batch growth cultures (Table 2) and on cell viability (Figure 1). In microbroth dilution inhibition assays, growth did not resume at MIC levels of SRE, SP22A, or SP22B after $48 \mathrm{~h}$ incubation indicating that these compounds were fungicidal (data not shown).

Table 1 | Minimal inhibitory concentrations (MICs) of SRE, SP22A, and SP25A against $S$. cerevisiae strains, lipid biosynthetic mutants, and C. albicans ATCC10231.

\begin{tabular}{|c|c|c|c|}
\hline \multirow[t]{2}{*}{ Yeast strains } & \multicolumn{3}{|c|}{$\operatorname{MIC}(\mu \mathrm{M})^{\dagger}$} \\
\hline & SRE & SP22A & SP25A \\
\hline \multicolumn{4}{|l|}{ S. cerevisiae } \\
\hline $\mathrm{KZ}-1 \mathrm{C}$ & 0.8 & 3.6 & $\wedge 6.5-13$ \\
\hline W303C & $\wedge 0.8-1.6$ & $\wedge 1.8-3.6$ & $\wedge 3.3-6.5$ \\
\hline$\Delta s y r 2$ & $\wedge 3.2-6.4$ & $\wedge 7.2-14.4$ & 13.0 \\
\hline$\Delta$ elo3 & $\wedge 1.6-3.2$ & $\wedge 3.6-7.2$ & $\wedge 6.5-13$ \\
\hline BY4741 & 0.8 & 1.8 & 3.3 \\
\hline$\Delta i p t 1$ & $\wedge 1.6-3.2$ & $\wedge 3.6-7.2$ & $\wedge 6.5-13$ \\
\hline$\Delta f a h 1$ & $\wedge 1.6-3.2$ & $\wedge 1.8-3.6$ & $\wedge 6.5-13$ \\
\hline$\Delta$ elo2 & $\wedge 1.6-3.2$ & $\wedge 3.6-7.2$ & $\wedge 6.5-13$ \\
\hline$\Delta s k n 1$ & $\wedge 1.6-3.2$ & $\wedge 3.6-7.2$ & $\wedge 6.5-13$ \\
\hline $8 \mathrm{~A}-1 \mathrm{~B}$ & 0.8 & 1.8 & 3.3 \\
\hline$\Delta e r g 3$ & 3.2 & 7.2 & 13 \\
\hline C. albicans ATCC 10231 & 3.2 & 3.6 & 6.5 \\
\hline
\end{tabular}

${ }^{+} \mathrm{MIC}$ values were obtained from at least two experiments each with triplicate determinations.

Two different values were obtained in replicate experiments.

\section{SUSCEPTIBILITY OF LIPID BIOSYNTHETIC MUTANTS}

Previous studies showed that certain $S$. cerevisiae mutants with defects in sphingolipid or sterol biosynthesis are more resistant to SRE than isogenic wild type strains (Grilley et al., 1998; Hama

Table 2 | Effects of SRE, SP22A, and SP25A on batch culture growth of S. cerevisiae strain KZ-IC.

\begin{tabular}{lll}
\hline Addition & Amount $(\boldsymbol{\mu M})$ & Generation time $(\mathbf{h})^{\dagger}$ \\
\hline None & 0.0 & 5.33 \\
SR & 0.8 & $\wedge$ \\
SP22A & 2.3 & 8.66 \\
& 4.7 & $\infty$ \\
& 9.3 & $\infty$ \\
SP25A & 2.1 & 6.3 \\
& 4.1 & 8.66 \\
& 8.2 & $\infty$
\end{tabular}

${ }^{+}$Calculated as 0.693 divided by the specific growth rate (cell doubling $h^{-1}$ ) during exponential growth. Mean values from three separate experiments. ${ }^{\wedge} \infty=$ Infinite.

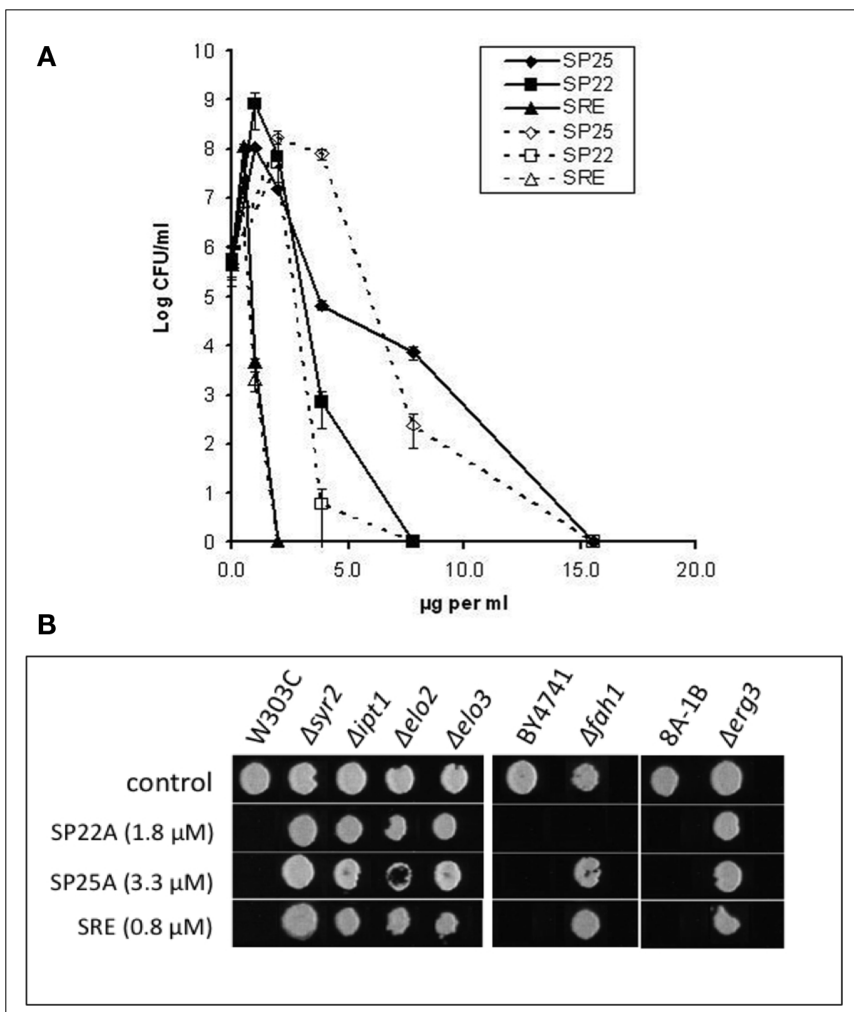

FIGURE 1 | Inhibition of yeasts and lipid mutants by syringopeptins and SRE. (A) Effects of SP25A ( $)$, SP22A ( $\mathbf{\square})$, and SRE ( $\mathbf{\Delta})$ at the designated concentrations on the viability of $C$. albicans (solid line) and $S$. cerevisiae strain $\mathrm{KZ}-1 \mathrm{C}$ (dashed lines). Error bars indicate SDs from average values from three separate experiments. (B) Effects on sphingolipid and ergosterol biosynthesis mutants and isogenic parental strains replica plated onto YPD agar with or without: SP22A $(1.8 \mu \mathrm{M})$, SP25A $(3.3 \mu \mathrm{M})$ or SRE $(0.8 \mu \mathrm{M})$. The plates were incubated at $28^{\circ} \mathrm{C}$ for $48 \mathrm{~h}$. 
et al., 2000; Stock et al., 2000). In the present study, mutant strains with genes deleted for dihydrosphingosine C-4 hydroxylase $(\Delta s y r 2)$, mannosyl-diinositolphosphoryl-ceramide synthase $(\Delta i p t 1)$, sphingolipid very long chain elongases ( $\Delta$ elo 2 and $\Delta$ elo3), and sterol C5,6 desaturase $(\Delta e r g 3)$ were each less susceptible to inhibition by SP22A and SP25A at MICs for their respective isogenic wild type parental strains (Table 1; Figure 1B). Mutant strain $\Delta$ fah 1 defective in sphingolipid fatty acid $\alpha$-hydroxylase was more susceptible to SP22A than to SRE or SP25A (Figure 1B) but nevertheless more resistant to SP22A concentrations below $2 \mu \mathrm{M}$ that were inhibitory to isogenic wild type strain BY4741 (Table 1). The inhibitory patterns suggest influences of target membrane lipids on the fungicidal action of SP22A and SP25A similar to those for SRE (Grilley et al., 1998; Hama et al., 2000; Stock et al., 2000; Kaulin et al., 2005). Although needed at higher concentrations with the mutants, the same relative inhibitory capabilities of SRE $>$ SP22A $>$ SP25A were observed regardless of the lipid biosynthesis defect.

\section{EFFECTS ON CELLULAR K+ AND CA ${ }^{2+}$ FLUXES}

As previously observed for SRE (Takemoto et al., 1991), SP22A, and SP25A caused net $\mathrm{K}^{+}$effluxes and $\mathrm{Ca}^{2+}$ influxes in whole cells of $S$. cerevisiae strain KZ1-1C (Figure 2). Higher concentrations of SP22A and SP25A were required to give the effects as compared to SRE. SRE stimulated $\mathrm{K}^{+}$efflux at concentrations starting from $1 \mu \mathrm{M}$; while 10 and $100 \mu \mathrm{M}$ of SP22A and SP25A, respectively, were required to achieve similar degrees of $\mathrm{K}^{+}$efflux. Cellular $\mathrm{Ca}^{2+}$ influx was observed within 15 min after $5 \mu \mathrm{M}$ SRE addition (data not shown). But, 40 and $120 \mu \mathrm{M}$ of SP22A and SP25A, respectively, were required for detection of $\mathrm{Ca}^{2+}$ influx. At these concentrations, $\mathrm{Ca}^{2+}$ influx was not evident until about 20 and 30 min after addition of SP22A and SP25A, respectively.

\section{CHANNEL FORMATION IN PLANAR LIPID BILAYERS}

SRE forms well-characterized voltage-dependent ion-conducting channels in lipid bilayers (Feigin et al., 1996; Kaulin et al., 1998; Malev et al., 2002). To examine whether the differences in the relative fungicidal capabilities of SRE, SP22A, and SP25A may lie in their different channel-forming properties, the conductances of planar lipid bilayers doped with the three compounds were compared (Figure 3). In all three cases, application of potentials negative from the side of lipodepsipeptide addition induced increases in macroscopic conductance. After a 5-min equilibration, the conductance reached its stationary value, which within the deviations expected for stochastically operating discrete pores, was stable for at least $10 \mathrm{~min}$ (Figure 3A). Application of positive voltages produced membrane conductance decreases (not shown), indicating closing of the pores. SRE produced smaller steady-state conductances at concentrations that were significantly higher ( $\sim 150$-fold) than those produced by the syringopeptins. SP22A induced slightly higher conductances than SP25A.

Single-channel recordings with all three lipodepsipeptides demonstrated a similar pattern (Figure 3B). In all cases, two types of single-channel conductance fluctuations were observed, small and large, differing in the levels of conductance five to sixfold as was described earlier for SRE (Malev et al., 2002; Kaulin et al., 2005). The dwell times of the large channels were longer than those

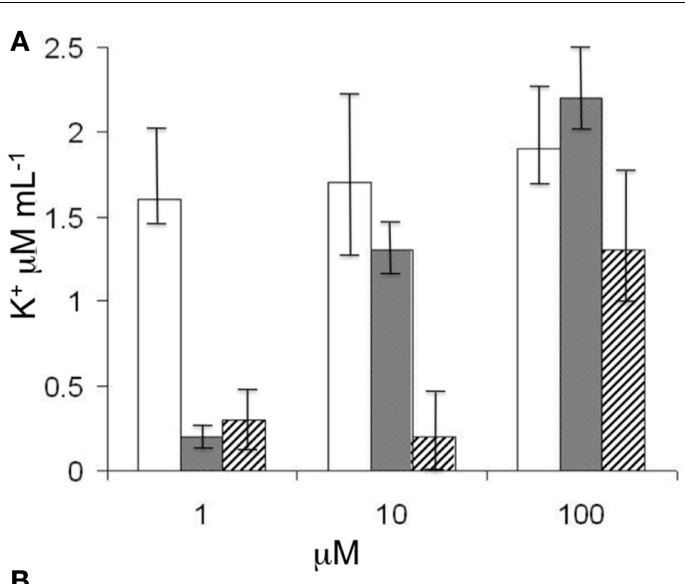

B

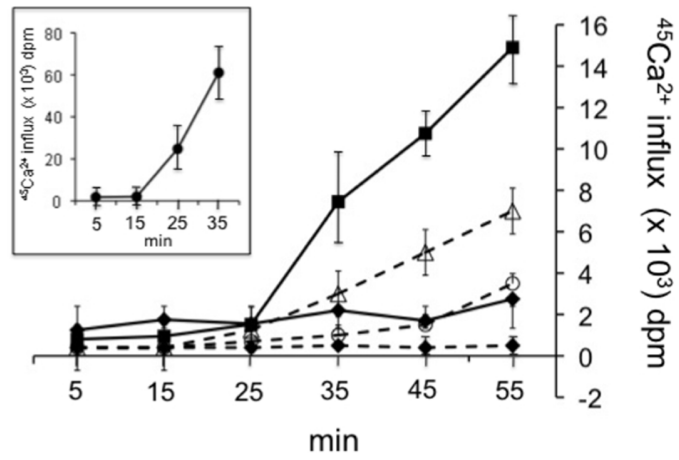

FIGURE 2 | Influence of syringopeptins on ion fluxes of yeast cells. (A) Effects of SRE (blank bars), SP22A (gray bars), and SP25A (striped bars) on $\mathrm{K}^{+}$efflux by yeast $S$. cerevisiae strain $\mathrm{KZ1-1C}$ cells growing in YPD medium. The cells were exposed to designated concentrations of SRE, SP22A, or SP25A and extracellular $\mathrm{K}^{+}$concentrations measured. Control efflux (no treatment) was similar to efflux with SP22A treatment at $1 \mu \mathrm{M}$. Error bars show relative SEs from three separate experiments. (B) Effects on ${ }^{45} \mathrm{Ca}^{2+}$ uptake by $S$. cerevisiae strain KZ1-1C cell suspensions. SRE, SP22A, and SP25A were added 5 min following addition of ${ }^{45} \mathrm{CaCl}_{2}$. SP22A (solid lines) concentrations were $10 \mu \mathrm{M}(\diamond)$ and $40 \mu \mathrm{M}(\boldsymbol{\square})$; SP25A (dashed lines) concentrations were $10 \mu \mathrm{M}(\diamond), 40 \mu \mathrm{M}(\mathrm{o})$, and $120 \mu \mathrm{M}(\triangle)$. Total $\mathrm{CaCl}_{2}$ concentration was $50 \mu \mathrm{M}$. SRE concentration was $5 \mu \mathrm{M}$ (inset). Error bars indicate SDs of average values from three separate experiments.

of the small ones. The values of the single-channel conductance for the small channels over the range of $\pm 200 \mathrm{mV}$ were close for all three lipodepsipeptides (Figure 3C). Thus, the properties of the single transmembrane channels, formed by SRE, SP22A, and SP25A were essentially the same.

\section{DISCUSSION}

SRE, SP22A, and SP25A caused cellular $\mathrm{K}^{+}$and $\mathrm{Ca}^{2+}$ fluxes at relative concentrations that paralleled their relative growth inhibitory activities against yeasts. The concentrations of these compounds needed to elicit the ion fluxes were higher than the corresponding MIC values suggesting that additional events are contributing to growth inhibition. It was also observed that SP22A and SP25A induced voltage-dependent conductance in planar lipid bilayers and that their yeast inhibitory capabilities were influenced by sphingolipid and sterol biosynthesis - phenomena characteristic 

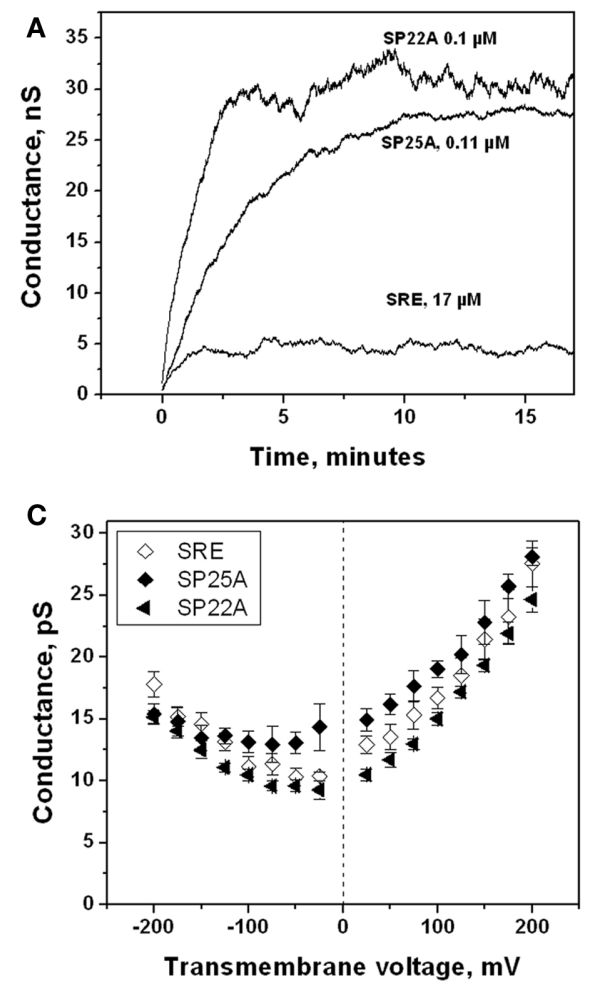

FIGURE 3 | (A) Time courses of the macroscopic ion conductance of bilayers doped with SRE, SP22A, and SP25A, recorded th the applied voltage of $-100 \mathrm{mV}$. Ten individual observations were made for each compound and concentration with one representative trace shown

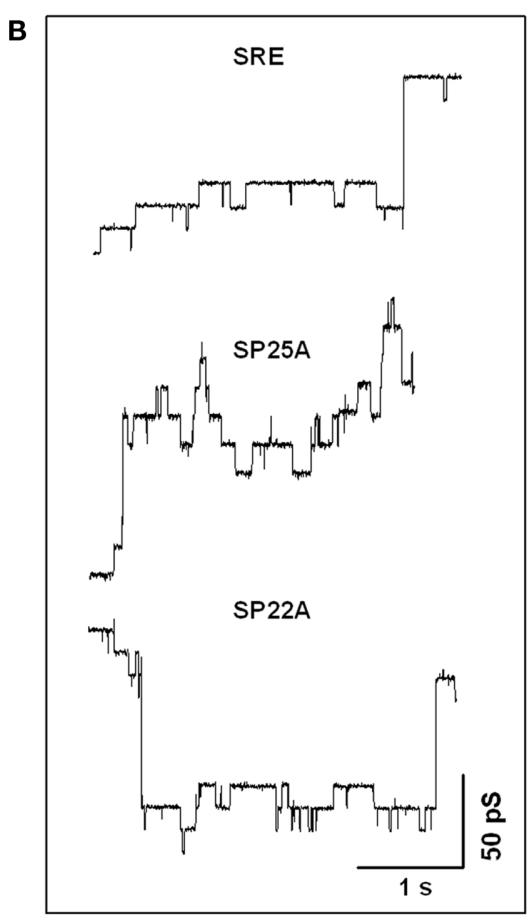

here. (B) Records of conductance fluctuations at $-150 \mathrm{mV}$ transmembrane voltage of SRE, SP22A, and SP25A-modified bilayers. (C) Conductance-voltage curves for SRE, SP22A, and SP25A small channels. of SRE effects (Feigin et al., 1996; Grilley et al., 1998; Hama et al., 2000; Stock et al., 2000). Therefore, based on what is known of SRE's mechanism of action (Malev et al., 2002; Takemoto et al., 2003; Kaulin et al., 2005), it is suggested that the syringopeptins form stable membrane pores comprised of and modulated by host membrane lipids and particularly sphingolipids and sterols.

The membrane channel properties of SP22A and SP25A were examined with planar lipid bilayers to explore the reasons for their lower yeast growth inhibitory activities as compared to SRE. Both syringopeptins turned out to be $\sim 150$ times more effective than SRE in inducing macroscopic conductance in DOPC bilayers. At the same time, the properties of the single channels formed by all three lipodepsipeptides were very similar (Figure 3) pointing to their similar structural organization (Ostroumova et al., 2007). It is suggested that the macroscopic conductance differences stem from the structural differences of SRE vs. the syringopeptins. SRE lacks a hydrophobic peptide domain, whereas SP22A and SP25A have hydrophobic peptide domains of 14 and 17 amino acids, respectively (Ballio et al., 1991). As a consequence, the syringopeptins are expected to interact more favorably with lipids than SRE. However, due to SP22A and SP25A increased hydrophobicities, their interaction with the yeast cell wall (Chaffin et al., 1998; Klis et al., 2006) might also be significantly increased thus boosting its filtering function. This additional barrier on their route to the plasma membrane may account for the discrepancy between their activities in planar lipid bilayers vs. growing cultures.

It is not known precisely how the syringopeptins and SRE interact with membrane lipids to form channels (Malev et al., 2002). However, the electrostatic and hydrophobic interactions between SP22A and membrane lipids are known to increase lipid ordering as a prelude to stable pore formation (Szabo et al., 2004). In addition, unlike SRE, the SP22A pores are not thermally inactivated suggesting a higher degree of affinity between SP22A and membrane lipids as compared to SRE (Szabo et al., 2004). It is therefore reasonable to assume that the lipid compositions of the yeast plasma membranes will influence stabilization of syringopeptin channel clusters differently from SRE channel clusters. This may constitute an additional component of the mechanistic basis for the different degrees of fungicidal activities of these lipodepsipeptides.

The present results emphasize the importance of the size and character of the hydrophobic moieties of these cyclic lipodepsipeptides in target cell specificity. SRE is mainly antifungal and the syringopeptins are antibacterial and phytotoxic as well (Iacobellis et al., 1992; Lavermicocca et al., 1997; Grgurina et al., 2005). It appears that the higher degree of hydrophobicity of the syringopeptins imparts a broader range of target cell specificity for plant-associated pseudomonads that produce these compounds. These bacteria are mainly plant epiphytes but also opportunistic 
plant pathogens, and their cyclic lipodepsipeptide profiles would influence the complex balance between pathogenicity and saprophytic existence.

In summary, the present studies show that like SRE the syringopeptins inhibit the growth of fungal yeasts and with similar physiological responses. Although they are less potent fungicides than SRE, the syringopeptins form lipid-modulated single channels in planar lipid bilayer membranes that are similar to those of SRE.

\section{REFERENCES}

Adetuyi, F. C., Isogai, A., Di Giorgio, D., Ballio, A., and Takemoto, J. Y. (1995). Saprophytic Pseudomonas syringae strain M1 of wheat produces cyclic lipodepsipeptides. FEMS Microbiol. Lett. 131, 63-67.

Agner, G., Kaulin, Y. A., Schagina, L. V., Takemoto, J. Y., and Blasko, K. (2000). Effect of temperature on the formation and inactivation of syringomycin E pores in human red blood cells and bimolecular lipid membranes. Biochim. Biophys. Acta 1466, 79-86.

Ballio, A., Barra, D., Bossa, F., Collina, A., Grgurina, I., Marino, G., Moneti, G., Paci, M., Pucci, P., Segre, A., and Simmaco, M. (1991). Syringopeptins, new phytotoxic lipodepsipeptides of Pseudomonas syringae pv. syringae. FEBS Lett. 291, 109-112.

Bensaci, M. F., and Takemoto, J. Y. (2007). Syringopeptin SP25Amediated killing of gram-positive bacteria and the role of teichoic acid d-alanylation. FEMS Microbiol. Lett. 268, 106-111.

Bidwai, A. P., Zhang, L., Bachmann, R. C., and Takemoto, J.Y. (1987). Mechanism of action of Pseudomonas syringae phytotoxin, syringomycin: stimulation of red beet plasma membrane ATPase activity. Plant Physiol. $83,39-43$.

Blasko, K., Schagina, L. V., Agner, G., Kaulin, Y. A., and Takemoto, J. Y. (1998). Membrane sterol composition modulates the pore forming activity of syringomycin $\mathrm{E}$ in human red blood cells. Biochim. Biophys. Acta 1373, 163-169.

Carpaneto, A., Dalla Serra, M., Menestrina, G., Fogliano, V., and Gambale, F. (2002). The phytotoxic lipodepsipeptide syringopeptin 25A from Pseudomonas syringae pv. syringae forms ion channels in sugar beet vacuoles. J. Membr. Biol. 188, 237-248.

Chaffin, W. L., López-Ribot, J. L., Casanova, M., Gozalbo, D., and Martínez, J. P. (1998). Cell wall and secreted proteins of Candida albicans: identification, function, and expression. Microbiol. Mol. Biol. Rev. $62,130-180$.

Cliften, P., Wang, Y., Mochizuki, D., Miyakawa, T., Wangspa, R.,
Hughes, J., and Takemoto, J. Y. (1996). SYR2, a gene necessary for syringomycin growth inhibition of Saccharomyces cerevisiae. Microbiology 142, 477-484.

Dalla Serra, M., Bernhart, I., Nordera, P., Di Giorgio, D., Ballio, A., and Menestrina, G. (1999). Conductive properties and gating of channels formed by syringopeptin 25A, a bioactive lipodepsipeptide from Pseudomonas syringae pv. syringae, in planar lipid membranes. Mol. Plant Microbe. Interact. 12, 401-409.

Di Giorgio, D., Camoni, L., and Ballio, A. (1994). Toxins of Pseudomonas syringae pv. syringae affect $\mathrm{H}+-$ transport across the plasma membrane of maize. Physiol. Plant. 91, 741-746.

Di Giorgio, D., Camoni, L., Mott, lio, A. (1996a). Syringopeptins, Pseudomonas syringae pv. syringae phytotoxins, resemble syringomycin in closing stomata. Plant Pathol. 45, 564-571.

Di Giorgio, D., Lavermicocca, P., Marchiafava, C., Camoni, L., and Surico, G., and Ballio, A. (1996b). Effect of syringomycin-E and syringopeptins on isolated plant mitochondria. Physiol. Mol. Plant Pathol. 48, 325-334.

Feigin, A. M., Takemoto, J. Y., Wangspa, R., Teeter, J. H., and Brand, J. G. (1996). Properties of voltagegated ion channels formed by syringomycin $\mathrm{E}$ in planar lipid bilayers. J. Membr. Biol. 149, 41-47.

Grgurina, I., Bensaci, M., Pocsfalvi, G., Mannina, L., Cruciani, O., Fiore, A., Fogliano, V., Sorensen, K. N., and Takemoto, J. Y. (2005). Novel cyclic lipodepsipeptide from Pseudomonas syringae pv. lachrymans strain 508 and syringopeptin antimicrobial activities. Antimicrob. Agents Chemother. (Bethesda) 49, 5037-5045.

Grilley, M., Stock, S. D., Dickson, R. C., Lester, R. L., and Takemoto, J. Y. (1998). Syringomycin action gene SYR2 is essential for sphingolipid 4-hydroxylation in Saccharomyces cerevisiae. J. Biol. Chem. 273, 11062-11068. K. A., Takemoto, J. Y., and Bal-

\section{ACKNOWLEDGMENTS}

This research was supported by the National Science Foundation (9003393), the Utah Agricultural Experiment Station (UTA 569; approved as journal paper no. 7972), the Intramural Research Program of the NIH, Eunice Kennedy Shriver National Institute of Child Health and Human Development, and an N. R. Gandhi Graduate Research Fellowship to Mekki F. Bensaci. We thank Dr. Joanne E. Hughes (Utah State University) for conducting ${ }^{45} \mathrm{Ca}^{2+}$ flux measurements.

Hama, H., Young, D. A., Radding, J. A., Ma, D., Tang, J., Stock, S. D., and Takemoto, J. Y. (2000). Requirement of sphingolipid alphahydroxylation for fungicidal action of syringomycin E. FEBS Lett. 478 , 26-28.

Hutchison, M. L., and Gross, D. C. (1997). Lipopeptide phytotoxins produced by Pseudomonas syringae pv. syringae: comparison of the biosurfactant and ion channel-forming activities of syringopeptin and syringomycin. Mol. Plant Microbe Interact. 10, 347-354.

Iacobellis, N. S., Lavermicocca, P., Grgurina, I., Simmaco, M., and Ballio A. (1992). Phytotoxic properties of Pseudomonas syringae pv. syringae toxins. Physiol. Mol. Plant Pathol. 40, 107-116.

Kaulin, Y. A., Schagina, L. V., Bezrukov, S. M., Malev, V. V., Feigin, A. M., Takemoto, J. Y., Teeter, J. H., and Brand, J. G. (1998). Cluster organization of ion channels formed by the antibiotic syringomycin $\mathrm{E}$ in bilayer lipid membranes. Biophys. J. 74, 2918-2925.

Kaulin, Y. A., Takemoto, J. Y., Schagina, L. V., Ostroumova, O. S., Wangspa, R., Teeter, J. H., and Brand, J. G. (2005). Sphingolipids influence the sensitivity of lipid bilayers to fungicide, syringomycin E. J. Bioenerg. Biomembr. 37, 339-348.

Klis, F. M., Boorsma, A., and De Groot, P. W. (2006). Cell wall construction in Saccharomyces cerevisiae. Yeast 23, 185-202.

Lavermicocca, P., Iacobellis, N., Simmaco, M., and Graniti, A. (1997). Biological properties and spectrum of activity of Pseudomonas syringae pv. syringae toxins. Physiol. Mol. Plant Pathol. 50, 129-140.

Malev, V. V., Schagina, L. V., Gurnev, P. A., Takemoto, J. Y., Nestorovich, E. M., and Bezrukov, S. M. (2002). Syringomycin E channel: a lipidic pore stabilized by lipopeptide? Biophys. J. 82, 1985-1994.

Montal, M., and Mueller, P. (1972). Formation of bimolecular membranes from lipid monolayers and a study of their electrical properties. Proc. Nat. Acad. Sci. U.S.A. 69, 3561-3566.
NCCLS. (2002). Reference Method for Broth Dilution Antifungal Susceptibility Testing of Yeast: Approved Standard, 2nd Edn. Wayne PA: National Committee for Clinical Laboratory Standards.

Ostroumova, O. S., Gurnev, P. A., Schagina, L. V., and Bezrukov, S. M. (2007). Asymmetry of syringomycin E channel studied by polymer partitioning. FEBS Lett. 581, 804-808.

Stock, S. D., Hama, H., Radding, J. A., Young, D. A., and Takemoto, J. Y. (2000). Syringomycin $\mathrm{E}$ inhibition of Saccharomyces cerevisiae: requirement for biosynthesis of sphingolipids with very-long-chain fatty acids and mannose- and phosphoinositolcontaining head groups. Antimicrob. Agents Chemother. (Bethesda) 44, 1174-1180.

Szabo, Z., Budai, M., Blasko, K., and Grof, P. (2004). Molecular dynamaction on model membranes: effects of syringopeptin22A, syringomycin $\mathrm{E}$, and syringotoxin studied by EPR technique. Biochim. Biophys. Acta 1660, 118-130.

Taguchi, N., Takano, Y., Julmanop, C., Wang, Y., Stock, S., Takemoto, J., and Miyakawa, T. (1994). Identification and analysis of the Saccharomyces cerevisiae SYR1 gene reveals that ergosterol is involved in the action of syringomycin. Microbiology $140(\mathrm{Pt}$ 2), 353-359.

Takemoto, J. Y., Brand, J. G., Kaulin, Y. A., Malev, V. V., Schagina, L. V., and Blasko, K. (2003). "The syringomycins: lipodepsipeptide pore formers from plant bacterium. Pseudomonas syringae," in Pore Forming Peptides and Protein Toxins, eds G. Menestrina, M. Dalla Serra, and P. Lazarovici (London: Taylor and Francis), 260-271.

Takemoto, J. Y., Zhang, L., Taguchi, N., Tachikawa, T., and Miyakawa, T. (1991). Mechanism of action of the phytotoxin, syringomycin: a resistant mutant of Saccharomyces cerevisiae reveals an involvement of $\mathrm{Ca}^{+}{ }^{+}$transport. J. Gen. Microbiol. 137, 653-659. ics of the cyclic lipodepsipeptides' 
Vassilev, V., Lavermicocca, P., Di Giorgio, D., and Iacobellis, N. S. (1996). Production of syringomycins and syringopeptins by Pseudomonas syringae pv. atrofaciens. Plant Pathol. 45, 316-322.

Zhang, L., and Takemoto, J. Y. (1989). Syringomycin stimulation of potassium efflux by yeast cells. Biochim. Biophys. Acta 987, 171-175.
Conflict of Interest Statement: The authors declare that the research was conducted in the absence of any commercial or financial relationships that could be construed as a potential conflict of interest.

Received: 18 August 2011; accepted: 11 October 2011; published online: 25 October 2011.
Citation: Bensaci MF, Gurnev PA, Bezrukov SM and Takemoto JY (2011) Fungicidal activities and mechanisms of action of Pseudomonas syringae pv. syringae lipodepsipeptide syringopeptins 22A and 25A. Front. Microbio. 2:216. doi: 10.3389/fmicb.2011.00216

This article was submitted to Frontiers in Fungi and Their Interactions, a specialty of Frontiers in Microbiology.
Copyright (C) 2011 Bensaci, Gurnev, Bezrukov and Takemoto. This is an openaccess article subject to a nonexclusive license between the authors and Frontiers Media SA, which permits use, distribution and reproduction in other forums, provided the original authors and source are credited and other Frontiers conditions are complied with. 